\title{
The potential of Olea europaea extracts to prevent TGF $\beta 1$-induced epithelial to mesenchymal transition in human nasal respiratory epithelial cells
}

Rabiatul Adawiyah Razali', Nik Ahmad Hafiz Nik Ahmad Eid', Turkambigai Jayaraman', Muhammad Asyrafi Amir Hassan', Nabilah Qistina Azlan', Nur Farhana Ismail', Nur Qisya Afifah Veronica Sainik', Muhammad Dain Yazid², Yogeswaran Lokanathan², Aminuddin Bin Saim³ and Ruszymah Bt Hj Idrus ${ }^{3 *}$

\begin{abstract}
Background: One of the molecular mechanisms involved in upper airway-related diseases is epithelial-tomesenchymal transition (EMT). Olea europaea (OE) has anti-inflammatory properties and thus, great potential to prevent EMT. This study aimed to investigate the effect of OE on EMT in primary nasal human respiratory epithelial cells (RECs).

Methods: Respiratory epithelial cells were isolated and divided into four groups: control (untreated), treated with $0.05 \%$ OE (OE group), EMT induced with $5 \mathrm{ng} / \mathrm{ml}$ of transforming growth factor beta-1 (TGF $\beta 1$ group) and treated with $5 \mathrm{ng} / \mathrm{ml}$ TGF $\beta 1+0.05 \%$ OE (TGF $\beta 1+$ OE group). The effects of OE treatment on growth kinetics, morphology and protein expression in RECs were evaluated. Immunocytochemistry analysis was performed to quantitate the total percentage of E-cadherin and vimentin expression from day 1 to day 3.

Results: There were no significant differences between untreated RECs and OE-treated RECs in terms of their morphology, growth kinetics and protein expression. Induction with TGF $\beta 1$ caused RECs to have an elongated spindle shape, a slower proliferation rate, a higher expression of vimentin and a lower expression of E-cadherin compared with the control. Cells in the TGF $\beta 1+$ OE group had similar epithelial shape to untreated group however it had no significant differences in their proliferation rate when compared to TGF $\beta 1$-induced RECs. Cells treated with TGF $\beta 1+$ OE showed significantly reduced expression of vimentin and increased expression of E-cadherin compared with the TGF $\beta 1$ group $(P<0.05)$.

Conclusion: The ability of OE to inhibit EMT in RECs was shown by TGFb1-induced EMT REC morphology, growth kinetics and protein expression markers (E-cadherin and vimentin) upon treatment with $\mathrm{OE}$ and TGF $\beta 1$. Therefore, this study could provide insight into the therapeutic potential of OE to inhibit pathological tissue remodelling and persistent inflammation.
\end{abstract}

Keywords: Olive, TGFß1, EMT, Vimentin, Circularity, E-cadherin

\footnotetext{
*Correspondence: ruszyidrus@gmail.com

${ }^{1}$ Department of Physiology, Faculty of Medicine, Universiti Kebangsaan

Malaysia Medical Centre, Universiti Kebangsaan Malaysia, Cheras, 56000 Kuala

Lumpur, Malaysia

Full list of author information is available at the end of the article
}

(c) The Author(s). 2018 Open Access This article is distributed under the terms of the Creative Commons Attribution 4.0 International License (http://creativecommons.org/licenses/by/4.0/), which permits unrestricted use, distribution, and reproduction in any medium, provided you give appropriate credit to the original author(s) and the source, provide a link to the Creative Commons license, and indicate if changes were made. The Creative Commons Public Domain Dedication waiver (http://creativecommons.org/publicdomain/zero/1.0/) applies to the data made available in this article, unless otherwise stated. 


\section{Background}

Chronic rhinosinusitis is a pathological disease due to inflammation of the sinonasal tract caused by infection or trauma. This long-term chronic inflammation will cause pathological changes in the mucosal epithelial layer, thus causing sinus ostium obstruction and symptoms such as nasal discharge, facial pain and even reduction of olfactory function [1-3]. This debilitating disease affects about $10.9 \%$ of the world's population [3] and significantly reduces the patient's quality of life [4]. The first line of treatment is usually antibiotics and a nasal decongestant with or without steroids. Failure of such treatment or the presence of obvious anatomical obstruction will eventually lead to sinus surgery to clear the obstruction and remove the diseased mucosal epithelium [5].

Several factors that could contribute to the pathogenesis of chronic rhinosinusitis are anatomic factors, allergies and viral or bacterial infections [2]. Respiratory epithelial cells (RECs) line the nasal airway and have an important function in mediating innate immunity to fight allergens and pathogens such as bacteria, viruses and fungi. Unfortunately, prolonged exposure and reaction to these pathological agents may lead to chronic inflammation and tissue remodelling.

Tissue remodelling is an important component of the response to inflammatory insult. It is a dynamic process involving dedifferentiation of epithelial cells, increased matrix production, degradation and subepithelial base membrane thickening [5, 6]. Differentiation of epithelial cells occurs when the cells change their phenotype from epithelial to mesenchymal through a normal reversible process called epithelial-to-mesenchymal transition (EMT) [6]. Epithelial cells will start to lose their typical morphology, polarity and junctional attachments and become motile. These occurrences are indicated by downregulation of expression of junctional proteins such as E-cadherin, ZO-1, claudins and occludin $[6,7]$. Additionally, these epithelial cells now acquire mesenchymal phenotypes such as expression of vimentin and $\alpha$-SMA due to rearrangement of cytoskeletal filaments that will prepare them to migrate.

There are three types of EMT [8, 9]. Type 1 EMT was associated with the primary mesenchymal cells going through mesenchymal-epithelial transition (MET) to form secondary epithelia which occurred during embryogenesis. Type 2 EMT happened during wound healing and organ regeneration which would help in tissue reconstruction. However, prolonged inflammation and insults will lead to fibrosis that was associated with Type 2 EMT. Type 3 EMT is associated with cancer progression and metastasis.

Insults to epithelial layer may cause injury or wound which will be repaired by the wound healing mechanisms and EMT. Epithelial cells undergoing EMT will become enlarged and migrate across the wound bed before they divide and proliferate to form a new epidermis layer $[10,11]$.

However, prolonged inflammation will cause alterations in the composition and organization of an organ due to continual EMT remodeling process, which eventually will lead to fibrogenesis $[5,11]$. Type 2 EMT has been associated with myofibroblast that expresses $\alpha$-SMA. This EMT epithelial cells or myofibroblasts travel through the basement membrane and accumulate at the tissue interstitium where they will synthesize matrix and collagens [11]. The dysregulation of injury-triggered EMT is believed to contribute to fibrosis of multiple organs, including those of the respiratory system [11].

Various growth and differentiation factors can induce or regulate EMT, including TGF- $\beta$, fibroblast growth factor, hepatic growth factor, platelet-derived growth factor and Wnt and Notch proteins [12]. However, TGF $\beta 1$ has been regarded as the most important growth factor for EMT due to its correlation with the extent of fibrosis and myofibroblast-like cell induction [13]. Upon TGF $\beta 1$ treatment, epithelial cells change their morphology from cuboidal to elongated spindle shaped; this is accompanied by increased cell motility, decreased expression of epithelial markers and increased expression of mesenchymal markers such as vimentin $[5,14,15]$.

In chronic rhinosinusitis, the epithelial layer shows a characteristic goblet cell hyperplasia, subepithelial oedema, inflammatory cell infiltration and fibrosis [16]. These would cause further epithelial damage, such as shedding and basement membrane thickening, which can cause physical and functional barrier defects $[5,6]$. Many studies have confirmed the loss of epithelial markers (e.g. E-cadherin) and gain of mesenchymal markers (e.g. vimentin) in chronic rhinosinusitis epithelial layers and the pathogenesis of nasal polyps, which shows that there are correlations between EMT and chronic rhinosinusitis with or without nasal polyps $[2,7,17]$. Therefore, one preventive method is to modulate EMT such that it does not cause severe tissue remodelling and persistent inflammation.

Several studies have demonstrated the ability of natural products to modulate EMT [18, 19]. Olea europaea, commonly known as olive, is a promising natural product with proven health benefits due to the presence of phenolics and flavonoids [20,21]. Olive is the fruit from the olive tree (Olea europaea L), which belongs to the family Oleaceae and is commonly included in the diet of Mediterranean people. The major phenolic compounds that have been identified and quantified in olive oil belong to three different classes: simple phenols (hydroxytyrosol, tyrosol); secoiridoids (oleuropein, the aglycone 
of ligstroside, and their respective decarboxylated dialdehyde derivatives) and lignans [(+)-1-acetoxypinoresinol and (+)- pinoresinol] [22].

Olive has been proven to have various benefits to consumers, including the ability to alter the structure of neurotoxic proteins that are believed to contribute to the debilitating effects of Alzheimer's disease [23] and the ability to impede and attenuate cell proliferation, invasiveness, fibrogenesis and EMT in breast cancer cell, kidney cells, and prostate cancers [24-26]. Besides that, olive also has been used traditionally in treating asthma, haemorrhoids, intestinal diseases and in reducing blood sugar and cholesterol [27]. However, no study on the effect of olive extract or its bioactive compound on EMT in nasal respiratory epithelial cells has been conducted.

Therefore, this study aimed to investigate the effects of olive extract on TGF $\beta 1$-induced EMT in human respiratory epithelial cells.

\section{Methods}

This study was approved by Universiti Kebangsaan Malaysia Research Ethics Committee (FF-2017-363).

\section{Human nasal REC isolation}

Redundant human nasal turbinate tissue was obtained with a written consent from four Asian patients who had undergone a turbinectomy procedure. Turbinate tissue was then washed with Dulbecco's Phosphate-Buffered Saline (DPBS) (Gibco, USA) to remove blood and mucus. Next, the epithelial layer was separated from the tissue and minced completely before being digested in $0.6 \% \mathrm{Col}-$ lagenase Type I (Worthington, USA) for $60 \mathrm{~min}$ in a shaker incubator at $37{ }^{\circ} \mathrm{C}$. After the tissue was fully digested, it was centrifuged for $5 \mathrm{~min}$ at $2370 \times g$. Then, the supernatant was discarded and the pellet washed with DPBS and re-centrifuged for $5 \mathrm{~min}$ at $2370 \times g$.

The cell pellets were suspended in growth medium consisting of Airway Epithelial Growth Medium (AEGM) (PromoCell, USA), Defined Keratinocyte Serum-Free Medium (DKSFM) (GIBCO, USA) and Dulbecco's Modified Eagle Medium: Nutrient Mixture F-12 (F12: DMEM) supplemented with 5\% Fetal Bovine Serum (FBS) (BioWest, USA), in a 1:1:2 ratio and seeded into a 6-well plate (Thermo Fischer, USA). All cells were then cultured at $37^{\circ} \mathrm{C}$ in $5 \% \mathrm{CO} 2$ incubator.

The medium was changed every 2 days until it reached $80-90 \%$ confluency. Subsequently, the co-culture of RECs and fibroblast was differentially trypsinized to remove fibroblasts from the culture plate. The medium was changed every 2 days until the cells reached $80-90 \%$ confluency before being trypsinized into passage 1 (P1) or passage 2 (P2), which were used as the experimental passages.

\section{Cytotoxicity assay}

The cytotoxic effect of commercially available Olea europaea (OE) extract (Olivenol plus+, CreAgri Inc., USA) was evaluated using the Vybrant $^{\mathrm{Tm}}$ MTT (3-(4,5-Dimethylthiazol-2-yl)-2,5-Diphenyltetrazolium Bromide) cell proliferation assay kit (Invitrogen, USA) following the manufacturer recommendations. Briefly, respiratory epithelial cells at passage 1 were grown in a 48-well plate and treated with several concentrations of OE extracts $(0,0.025,0.05,0.1,0.15,0.2,0.4 .1$ and $2 \%$ $(v / v)$ for $24 \mathrm{~h}$. Subsequently, OE-treated RECs medium were removed and replaced with $200 \mu \mathrm{l}$ of fresh medium. About $20 \mu \mathrm{l}$ of MTT solution were added to the well and incubated for $4 \mathrm{~h}$ at $37^{\circ} \mathrm{C}$ before $200 \mu \mathrm{l}$ of sodium dodecyl sulphate-hydrogen chloride (SDS-HCL) solution was added and were further incubated for another $4 \mathrm{~h}$. All of the solution in the well were divided into two replicates and about $210 \mu \mathrm{l}$ of solution was transferred into 1 well of 96-well plates before the absorbance was read at $570 \mathrm{~nm}$. Four samples were assayed in triplicate for this experiment. One optimum concentration was chosen to be used for further experimentation.

\section{Quantification of total cell attached}

Respiratory epithelial cells were observed $24 \mathrm{~h}$ after TGF $\beta 1$ induction. In order to profile the growth of TGF $\beta 1$ induced RECs, about five independent fields of REC images were captured [28]. The total number of cells attached to the surface was calculated and quantitated following the equation below:

$$
\text { Total cells attached }=\frac{\text { Average cell count }}{\text { Objective area of the microscope }}
$$

\section{Immunocytochemical analysis}

Expression levels of E-cadherin and vimentin were evaluated using immunocytochemical analysis [25]. Cells were washed with DPBS, fixed with $4 \%$ paraformaldehyde (PFA) for $30 \mathrm{~min}$ (Sigma-Aldrich, USA), permeabilized for $20 \mathrm{~min}$ with $0.5 \%$ Triton $\mathrm{X}-100$ solution (Sigma-Aldrich) and then blocked with $10 \%$ goat serum for $1 \mathrm{~h}$ at $37{ }^{\circ} \mathrm{C}$. The cells were then incubated with 1:200 mouse anti-E-cadherin antibody (ab1416) and 1:2000 rabbit anti-Vimentin antibody (ab92547) (Abcam, USA) overnight at $4{ }^{\circ} \mathrm{C}$. On the following day, the cells were washed before being incubated with 1:300 diluted Alexa Fluor 594 anti-rabbit IgG (Invitrogen, USA) and Alexa Fluor 488 anti-mouse (Invitrogen) for $1 \mathrm{~h}$ at $37{ }^{\circ} \mathrm{C}$. Nuclei were counterstained with DAPI. Fluorescence images were captured with a Nikon Eclipse Ti fluorescence microscope (Nikon, Japan). The total number of cells expressing vimentin was calculated from five independent fields of images following the same equation above. 


\section{Olea europaea supplementation}

Passage 2 RECs at about 40\% confluency were seeded into four different conditions, namely control (untreated RECs only), $0.05 \%$ OE (RECs treated with Olea europaea extract) (CreAgri Inc., USA), TGF $\beta 1$ (RECs induced with $5 \mathrm{ng} / \mathrm{ml}$ TGF $\beta 1$ ) and TGF $\beta 1+\mathrm{OE}$ (RECs treated with $0.05 \%$ Olea europaea extract and induced with $5 \mathrm{ng} / \mathrm{ml}$ TGF $\beta 1$ ). All control and treatment groups were subjected to morphological assessment [29], growth kinetic quantification [28] and immunocytochemical analysis [25].

\section{Morphology assessment}

Morphological observation of RECs was performed for 72 h. Images were captured daily with a Nikon A1R Confocal microscope (Nikon, Japan). Cell circularity was quantitated using ImageJ (version 1.51j8, National Institutes of Health, USA) at day 3 of induction. Cellular morphology was assessed based on the value of circularity where a value approaching 0 indicated an elongated shape, and as the value increased to 1 , the shape became more circular.

\section{Cell proliferation and growth kinetics}

About five independent fields of REC images were captured at $0,24,48$ and $72 \mathrm{~h}$. Total numbers of cells attached at the aforementioned time points were calculated. The proliferation rate and population doubling time (PDL) were calculated using the following formula:

$$
\begin{gathered}
\text { Proliferation rate }(\mathrm{h})^{-1}=\frac{\ln (\text { Total cells attached (final) } / \text { Total cells attached (initial) }}{\text { Time }} \\
\operatorname{PDL}=\frac{(\text { Time } \mathrm{x} \log (2))}{\log (\text { total cells attached }(\text { final })-\log (\text { total cells attached (initial) })}
\end{gathered}
$$

\section{Statistical analysis}

Experiments were performed in triplicate and repeated on at least three biological samples $(n=3)$, and data are presented as mean \pm SEM. For statistical analysis, ANOVA was used. Statistical analysis was performed using Prism Version 7.0 software (GraphPad, Software Inc., USA). Results were considered statistically significant at $P<0.05$. All values are expressed as mean \pm SEM.

\section{Results}

\section{OE increases REC proliferation}

The MTT assay was performed to examine the effects of OE on normal human RECs. Treatment with $0.05 \%$ OE was found to significantly increase the total number of viable RECs by $24 \%$ compared with the control. However, there was a significant concentration-dependent inhibition of cell proliferation starting from $0.4 \% \mathrm{OE}$, with an inhibitory concentration $50\left(\mathrm{IC}_{50}\right)$ of $0.69 \%$ (Fig. 1a). Moreover, as the percentage of OE increased above $0.6 \%(v / v)$, RECs started to become rounded and shrunken (Fig. 1b). This assay also showed that $0.05 \%$ OE has a positive effect on cell viability and proliferation of RECs. Therefore, it was chosen as the selected concentration to be used throughout the experiment.

\section{TGF $\beta 1$ causes primary RECs to undergo EMT}

In order to develop an EMT model, three concentrations of TGF $\beta 1$ were used to evaluate both epithelial and mesenchymal expression markers (Fig. 2). After induction of RECs with TGF $\beta 1$ for $24 \mathrm{~h}$, all RECs that had undergone TGF 1 1-induced EMT appeared larger and elongated, similar in shape to mesenchymal cells. Moreover, RECs in the 5,10 , and $20 \mathrm{ng} / \mathrm{ml}$ TGF $\beta 1$-induced EMT group were lower in number $\left(1.8 \times 10^{4} \pm 6.2 \times 10^{3}, 1.7 \times 10^{4} \pm\right.$ $4.7 \times 10^{3}, \quad 1.7 \times 10^{4} \pm 1.2 \times 10^{3}$ cells $/ \mathrm{cm}^{2}$ respectively) than those in the untreated group $\left(2.4 \times 10^{4} \pm\right.$ $9.1 \times 10^{3} \mathrm{cells} / \mathrm{cm}^{2}$ ). Immunocytochemical analysis of E-cadherin and vimentin showed that, upon treatment with 5,10 , and $20 \mathrm{ng} / \mathrm{ml}$ of TGF $\beta 1$, E-cadherin expression was significantly lower $(33.2 \% \pm 2.5,32 \% \pm 3.4$ and $26.4 \% \pm 2.5$ respectively), whereas vimentin expression was significantly higher $(55.8 \% \pm 2.8,56 \% \pm 2.6$, and $55.6 \% \pm 2.8$ respectively), compared with untreated RECs (E-cadherin: $53 \% \pm 2.5$ and vimentin: $43 \% \pm 1.2$ ). As induction with $5 \mathrm{ng} / \mathrm{ml}$ TGF $\beta 1$ could induce RECs to undergo EMT, this concentration was chosen to be used throughout this experiment.

OE increases the circularity of RECs with TGF $\beta 1$-induced EMT The morphology of treated and untreated RECs was observed, and circularity analysis was performed to quantify morphological changes. Respiratory epithelial cells treated with $0.05 \%$ OE were more circular $(0.865 \pm$ $0.002)$ than control RECs $(0.832 \pm 0.002)$. However, upon treatment with $5 \mathrm{ng} / \mathrm{ml}$ of TGF $\beta 1$, RECs were found to become spindle-shaped $(0.717 \pm 0.005)$, resembling mesenchymal cells. Interestingly, RECs treated with TGF $\beta 1$ and $\mathrm{OE}$ were found to be more circular $(0.886 \pm 0.002)$ than control cells and TGF $\beta 1$-induced RECs without OE (EMT RECs) (Fig. 3).

\section{TGF $\beta$ 1-induced REC proliferation is not affected by OE treatment}

There was a significant increase in the total cell number of untreated RECs and in the OE-treated group at $48 \mathrm{~h}$ and $72 \mathrm{~h}$ compared with $0 \mathrm{~h}$. The TGF $\beta 1$ and TGF $\beta 1+$ OE groups showed a significant increase in total cell number only after $72 \mathrm{~h}$ (Fig. 4b). The untreated REC group had a higher proliferation rate $\left(0.03 \mathrm{~h}^{-1} \pm 0.002\right)$ than the OE, TGF $\beta 1+\mathrm{OE}$ and TGF $\beta 1$ groups, with a population doubling time (PDL) of $24 \mathrm{~h} \pm 2 \mathrm{~h}$. This was followed by the OE group $\left(0.019 \mathrm{~h}^{-1} \pm 0.001\right)$, with a PDL of $37 \mathrm{~h} \pm 2 \mathrm{~h}$ (Fig. 4c). However, the proliferation rates in the TGF $\beta 1$ group and the TGF $\beta 1+$ OE group 


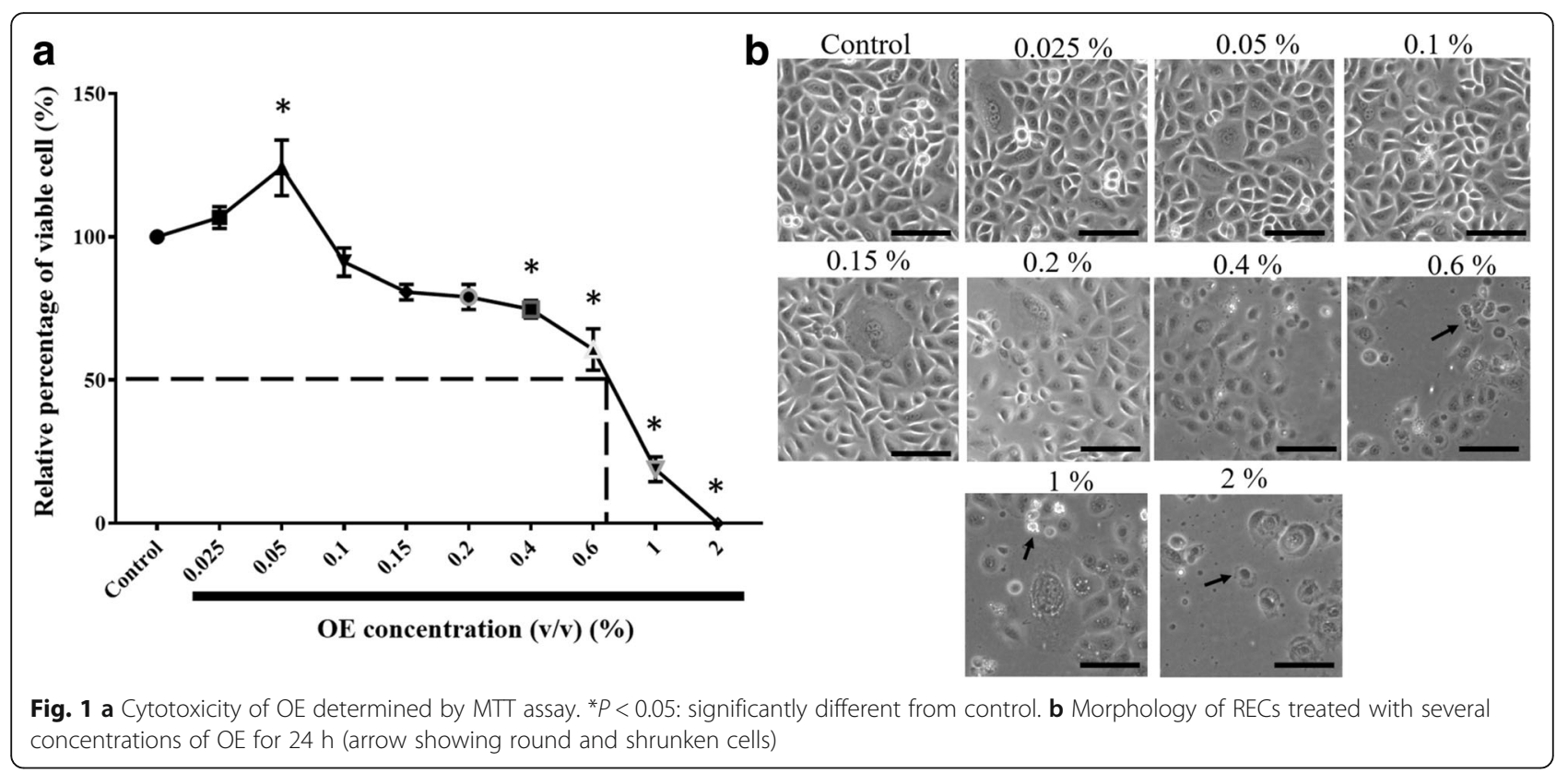

were significantly lower compared with the control $\left(0.011 \mathrm{~h}^{-1} \pm 0.003\right.$ and $0.015 \mathrm{~h}^{-1} \pm 0.005$, respectively) with PDL of $91 \mathrm{~h} \pm 42 \mathrm{~h}$ and $72 \mathrm{~h} \pm 37 \mathrm{~h}$, respectively.

\section{OE reduces vimentin expression in TGF $\beta 1$-induced RECs}

Figure 5 shows the expression of vimentin in each treatment group. At $24 \mathrm{~h}$, there were no significant differences in vimentin expression between all tested groups. However, at $48 \mathrm{~h}$ TGF $\beta 1$ was found to significantly increase vimentin expression by RECs $(90.81 \% \pm$ 1.27) compared with the control $(61.18 \% \pm 5.05)$ and $\mathrm{OE}$ groups $(59.59 \% \pm 7.49)$ (Fig. 5b). After $72 \mathrm{~h}$, a significant $22 \%$ reduction in vimentin expression was seen in the $\mathrm{TGF} \beta 1+\mathrm{OE}$ group $(72.00 \% \pm 3.54)$ compared with

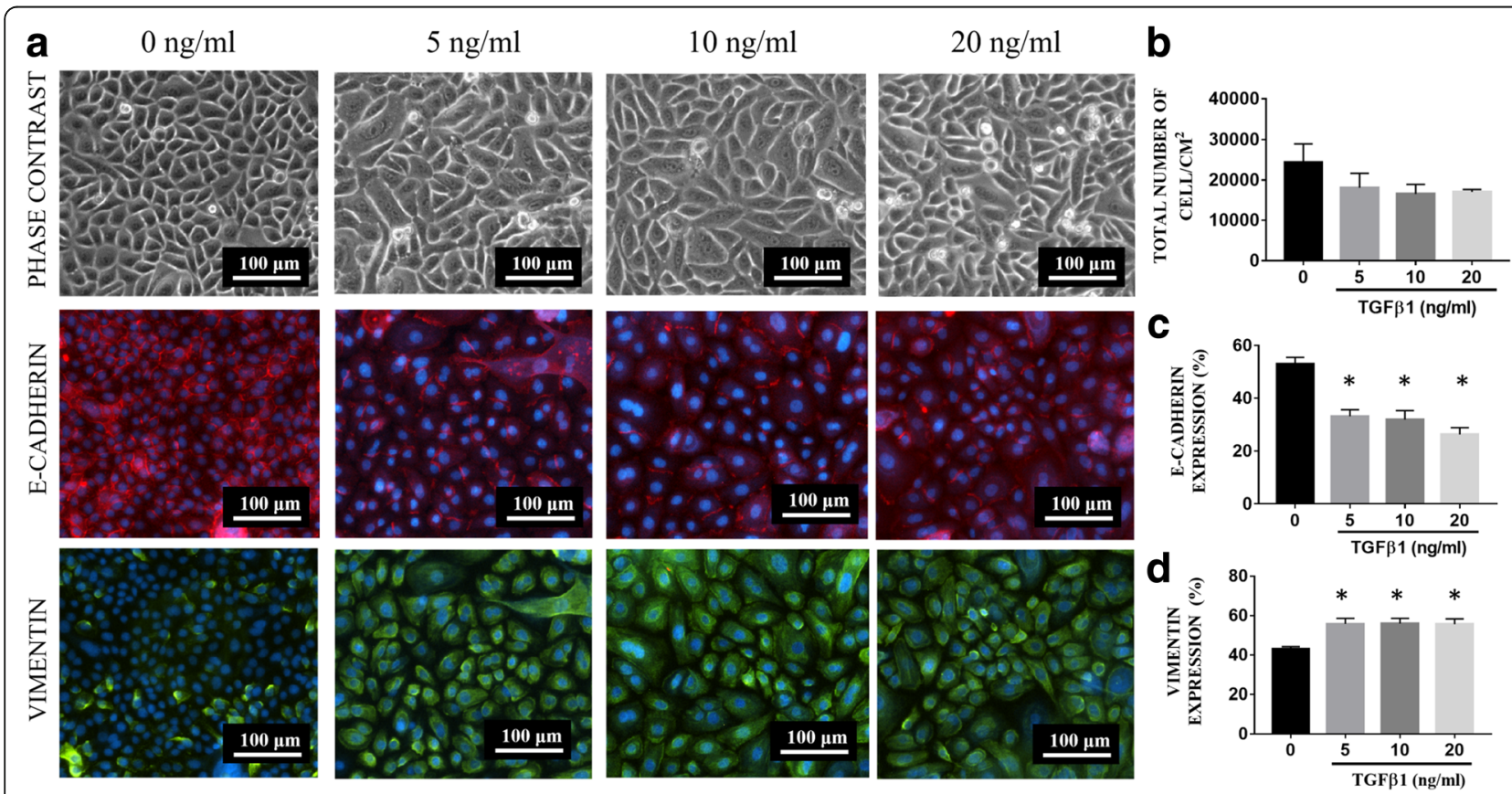

Fig. 2 a Phase-contrast and fluorescence microscope image of RECs treated with 0, 5, 10 and $20 \mathrm{ng} / \mathrm{ml}$ of TGF $\beta 1$. b Total number of cells after a $24-\mathrm{h}$ treatment with $0,5,10$ and $20 \mathrm{ng} / \mathrm{ml}$. There is a reduction in the total number of cells after $24 \mathrm{~h}$ of treatment in all the experimental groups compared with the control $(0 \mathrm{ng} / \mathrm{ml})$. $\mathbf{c}$ Vimentin expression. $\mathbf{d}$ E-cadherin expression. ${ }^{*} P<0.05$ indicates a significant difference compared with the control 
a

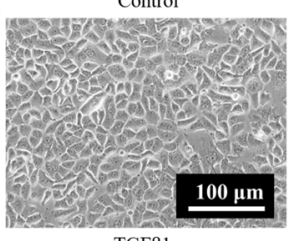

TGF $\beta 1$

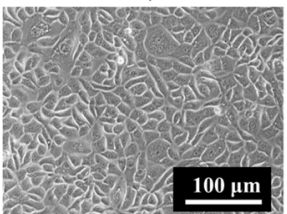

$\mathrm{OE}$

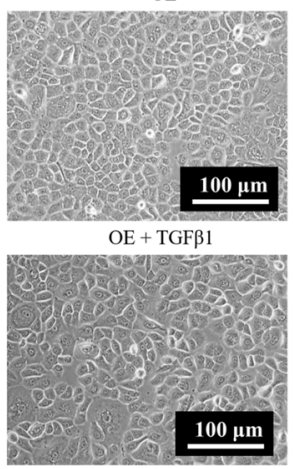

b

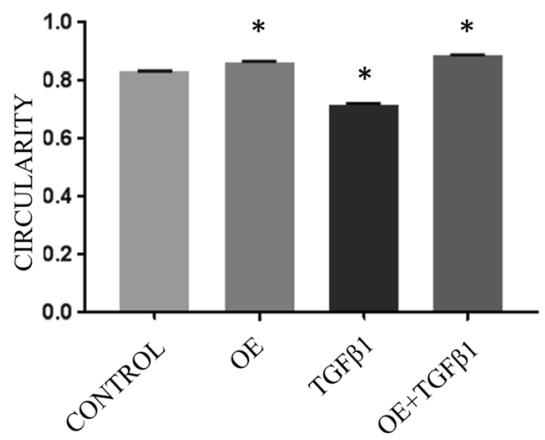

Fig. 3 a Morphology of untreated RECS (control), $0.05 \%$ OE-treated RECS (OE), RECs with EMT induced by $5 \mathrm{ng} / \mathrm{ml}$ TGF $\beta 1$ (TGF $\beta 1$ ) and RECs with EMT induced by TGF $\beta 1$ treated with OE (TGF $\beta 1+\mathrm{OE})$ on day 3. The TGF $\beta 1$ group displays a more elongated structure than the OE and TGF $\beta 1+$ OE groups. b Cell circularity as analyzed using ImageJ software. ${ }^{*} P<0.05$ indicates significant difference compared with control

a
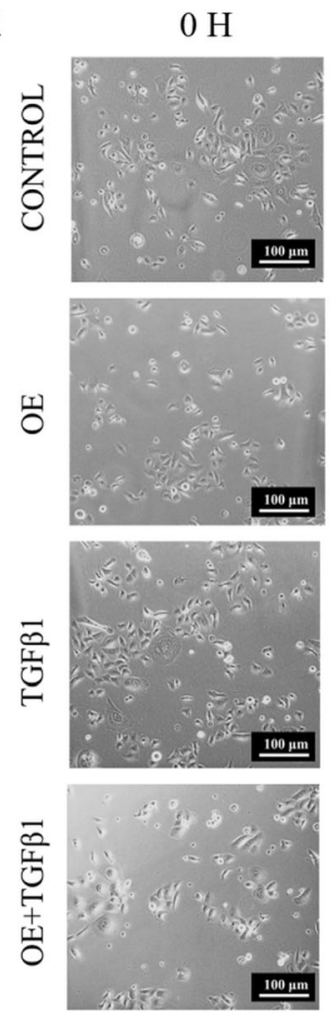

b

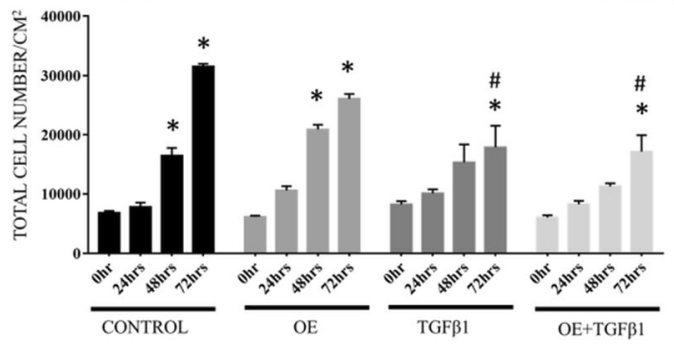

$48 \mathrm{H}$
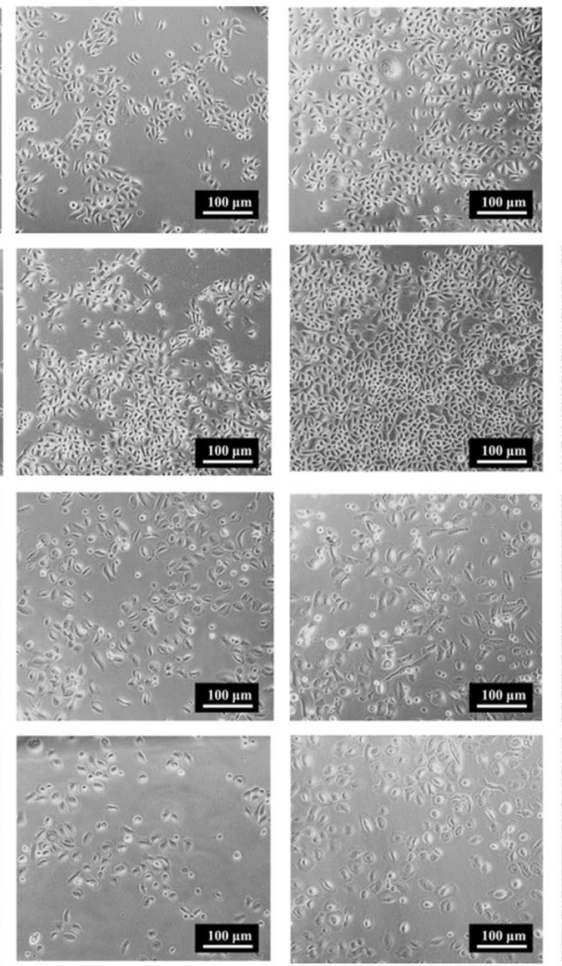

\section{$72 \mathrm{H}$}

C

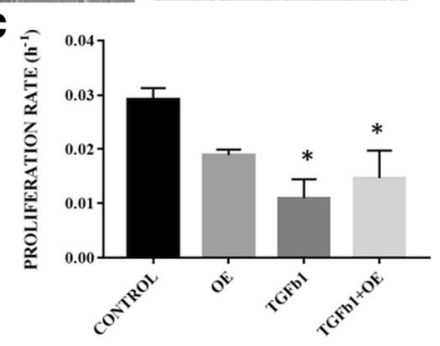

Fig. 4 a Distribution of untreated RECs (control), $0.05 \%(v / v)$ OE-treated RECs (OE), RECs induced to EMT with $5 \mathrm{ng} / \mathrm{ml}$ TGF $\beta 1$ (TGF $\beta 1)$ and RECs induced to EMT with TGF $\beta 1$ and treated with OE (TGF $\beta 1+$ OE) from $0 \mathrm{~h}$ to $72 \mathrm{~h}$. $\mathbf{b}$ Total cell number $/ \mathrm{cm}^{2}$ versus (vs) time per group. ${ }^{*} P<0.05$ indicates significant difference when compared with $0 \mathrm{~h}$ and $\# P<0.05$ indicates significant difference when compared with the control group. $\mathbf{c}$ The proliferation rate of cells. ${ }^{*} P<0.05$ indicates significant difference when compared with the control 


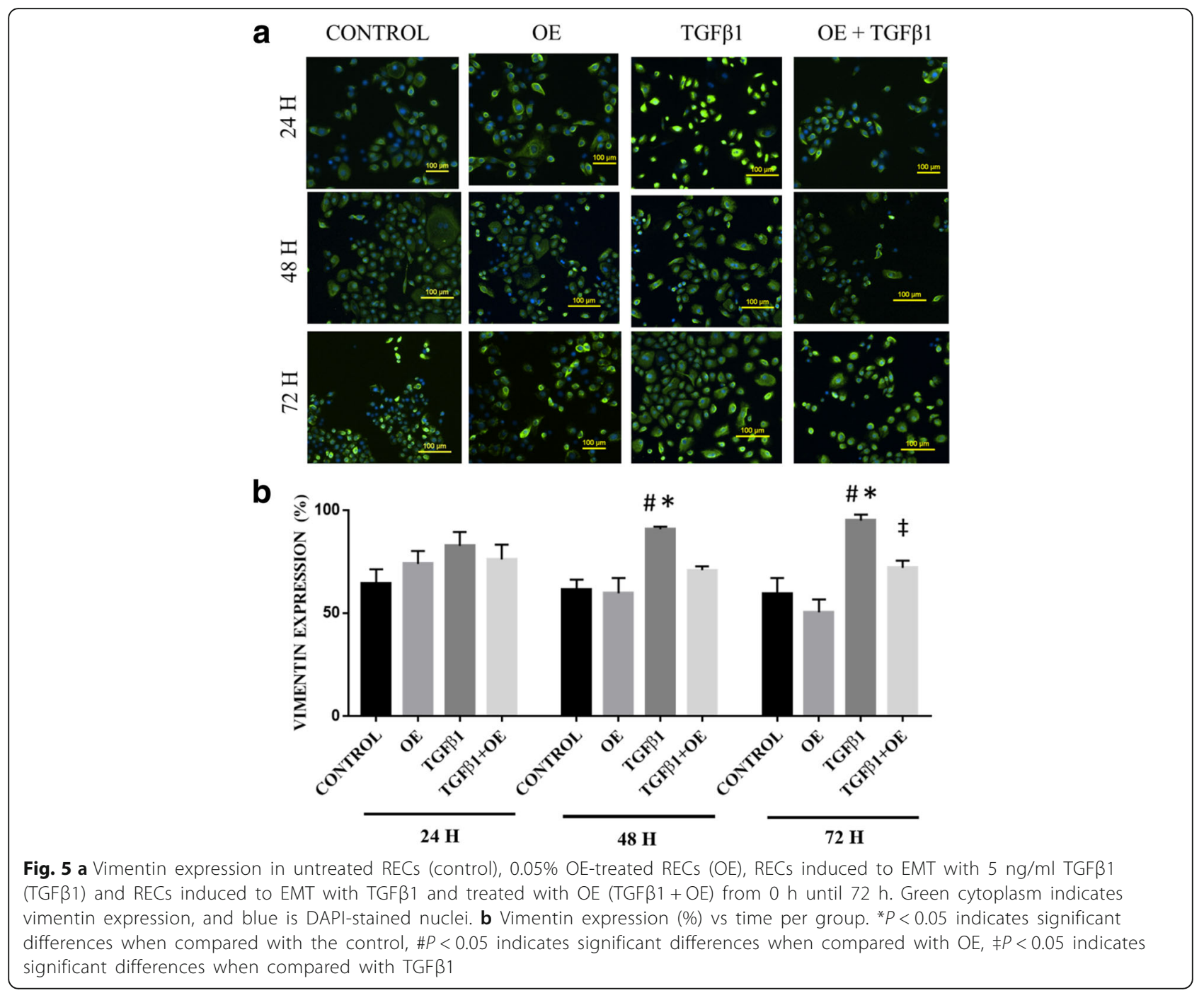

TGF $\beta 1$-induced RECs $(94.95 \% \pm 2.94)$. There were no significant differences in vimentin expression in RECs treated with OE compared with untreated RECs (control).

\section{OE increases E-cadherin expression in TGF $\beta 1$-induced RECS}

After a $24 \mathrm{~h}$ incubation, there were no significant differences in E-cadherin expression between all tested groups. Respiratory epithelial cells that underwent TGF $\beta 1$-induced EMT had lower E-cadherin expression after $48 \mathrm{~h}(9.19 \% \pm 1.27)$ of TGF $\beta 1$ treatment compared with untreated RECs $(38.82 \% \pm 5.05)$ and the OE group $(40.41 \% \pm 7.49)$ (Fig. 6). There were no significant differences in E-cadherin expression in the TGF $\beta 1+\mathrm{OE}$ group compared with that of untreated RECs and the OE group at $24 \mathrm{~h}$ and $48 \mathrm{~h}$. However, at $72 \mathrm{~h}$, E-cadherin expression was higher in the TGF $\beta 1+\mathrm{OE}$ group $(27.99 \% \pm 3.54)$ compared with TGF $\beta 1$-induced RECs $(5.05 \% \pm 2.94)$.

\section{Discussion}

Persistent injury and inflammation to the respiratory epithelial layer due to infection or allergens can cause fibrosis, thickening of the subepithelial membrane and an impaired nasal epithelial barrier. These alterations are known to cause damage to the nasal epithelium and contribute to nasal polyp formation [25]. Changes that occur during insults can be marked by the activation of EMT, where the epithelial cells lose their epithelial phenotype and become mesenchymal cells, which can lead to changes in epithelial morphology. This occurrence can be investigated by observing the decreasing expression of epithelial protein markers such as E-cadherin and ZO-1 and increasing expression of mesenchymal markers such as vimentin. E-cadherin is an important component for epithelial adherence junction. Reduction in the expression of E-cadherin protein marked the initiation of EMT where cells detached from one another and started 

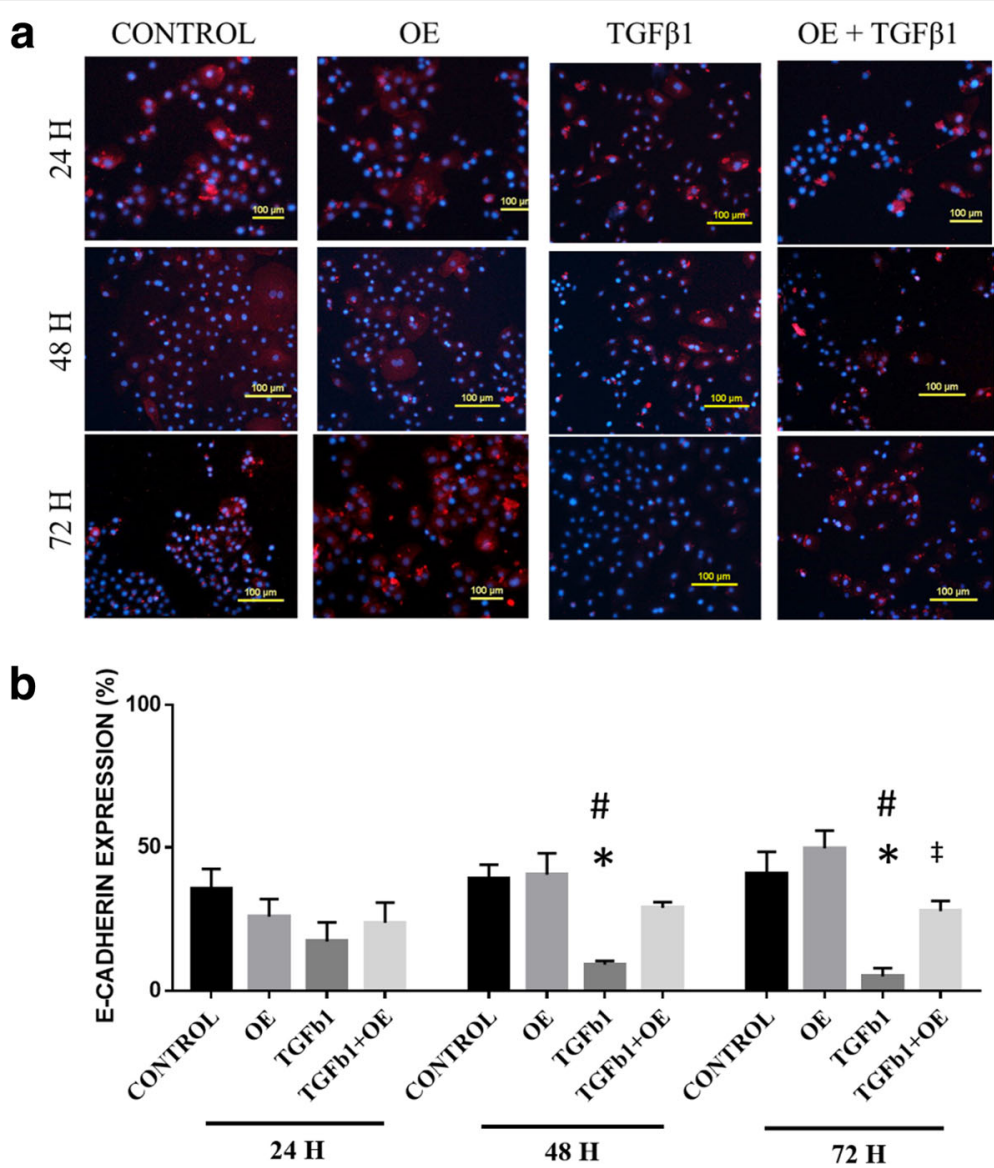

Fig. 6 a E-cadherin expression in untreated RECs (control), 0.05\% OE-treated RECS (OE), RECs induced to EMT with 5 ng/ml TGF $\beta 1$ (TGF $\beta 1$ ) and RECs induced to EMT with TGF $\beta 1$ and treated with OE (TGF $\beta 1+O E)$ from $0 \mathrm{~h}$ until $72 \mathrm{~h}$. Red colour indicates E-cadherin expression, and blue is the nucleus. $\mathbf{b}$ E-cadherin expression (\%) at various time points. ${ }^{*} P<0.05$ indicates significant differences when compared with the control, $\# P<0.05$ indicates significant differences when compared with $\mathrm{OE}, \neq P<0.05$ indicates significant differences when compared with TGF $\beta 1$

the migration process [30]. Meanwhile, vimentin is a critical mesenchymal markers that are highly elevated during EMT which indicated changes in phenotype of cells from epithelial to mesenchymal [8]. In this study, we examined the potential of Olea europaea extract (OE) to prevent TGF $\beta 1$-induced EMT in human RECs.

We have observed concentration-dependent effects of OE on RECs, in which $0.05 \%(v / \mathrm{v})$ OE increased REC proliferation. Reduction of proliferation of RECs began at $0.4 \%(\mathrm{v} / \mathrm{v}) \mathrm{OE}$, indicating that RECs were undergoing apoptosis $\left(\mathrm{IC}_{50}=0.69 \%\right)$. Therefore, in this study, we used $\mathrm{OE}$ at a concentration of $0.05 \%$. Olive at suitable concentrations has been observed to have selective activity whereby it increases proliferation of normal non-disease cells while causing death in diseased cells [31, 32].

Treatment with OE did not cause any changes in RECs in terms of protein expression and morphology. Interestingly, OE maintained the cuboidal shape of RECs, while retaining higher expression of E-cadherin and lower vimentin expression, similar to untreated RECs. Vimentin expression levels in untreated RECs were consistent with a previous study [33], which showed that healthy inferior turbinates have lower expression of vimentin than nasal polyps.

In order to evaluate the potential of $\mathrm{OE}$ to prevent EMT, an EMT-induced model of RECs was developed by TGF $\beta 1$ induction (Fig. 2). Upon TGF $\beta 1$ induction, RECs showed reduction of cell proliferation (Fig. 4b) and changes in morphology from a cobblestone-like shape to a spindle shape (Fig. 3). In order to confirm whether those changes were an indication of EMT, the expression levels of vimentin and E-cadherin were investigated. Our results showed that RECs induced with TGF $\beta 1$ have lower expression of E-cadherin and higher expression of vimentin compared with controls, in line with the findings of several previous studies, which showed that, upon treatment with TGF $\beta 1$, epithelial cells, for example, Madin-Darby canine kidney (MDCK) 
cells displayed increased vimentin expression and reduced E-cadherin expression $[25,26]$.

TGF $\beta 1$ is known as an EMT inducer that predominantly targets Smad-dependent pathway activation [34]. Binding of TGF $\beta$ to TGF $\beta$ receptor will activate its downstream protein via a series of phosphorylation events of Smad 2 and Smad 3, which consequently form trimers with Smad 4. This complex is then translocated to the nucleus and will activate the transcription of target genes, for example, Snail, Zeb, FOXA1, PRX1 and Twist. These transcription factors will bind to the E-cadherin promoter, repress its transcription and simultaneously upregulate mesenchymal markers (vimentin) $[35,36]$.

In this study, the potential of OE to inhibit EMT when present together with an EMT induction factor was evaluated. Upon OE treatment of RECs undergoing TGF $\beta 1$-induced EMT, it was observed that OE helps to retain the cuboidal shape of RECs, hence preventing the effect of TGF $\beta 1$. However, after treatment with OE for $72 \mathrm{~h}$, the vimentin expression of untreated RECs showed significant reduction compared with that of RECs undergoing TGF $\beta 1$-induced EMT. This might suggest that OE helps RECs to re-establish vimentin and E-cadherin expression; thus, OE has the potential to prevent EMT. There is less evidence on how and where Olea europeae targets the EMT signaling pathway. However, a previous study showed that treatment of OE inhibits the upregulation of SMAD4 and SNAIL2 (Slug), TCF4, VIM (Vimentin), FN (fibronectin) and SERPINE1 genes in a breast cancer cell line and MDCK cells [25]. Future work involving markers of the EMT signalling pathway looking at their expression could be beneficial to a greater understanding of the effects of OE on EMT.

\section{Conclusion}

Our findings suggest that Olea europeae extract has the ability to prevent EMT by maintaining the epithelial phenotype. This proves that Olea europeae has the potential to modulate EMT and hence, can prevent persistent inflammation and tissue remodeling as in chronic rhinosinusitis. More studies using in vivo disease models are needed to confirm the utility of Olea europeae as an alternative treatment for airway diseases.

\section{Abbreviations}

AEGM: Airway epithelial growth medium; DPBS: Dulbecco's PhosphateBuffered Saline; EMT: Epithelial-to mesenchymal transition; F12:DMEM: Dulbecco's Modified Eagle Medium: Nutrient Mixture F-12; FBS: Fetal Bovine Serum; h: Hours; $I_{50}$ : Inhibitory concentration; MDCK: Madin-Darby canine kidney; OE: Olive extract; PFA: Paraformaldehyde: RECS: Respiratory epithelial cells; SEM: Standard error of mean; TGF $\beta 1$ : Transforming growth factor $\beta 1$

\section{Acknowledgements}

The authors would like to thank Miss Bavithara Karunagaran for her contribution to this research. This study was funded by grants provided by National University of Malaysia (FF-2017-020, FF-2017-363 and FF-2017-273).

\section{Funding}

This study was funded by grants provided by National University of Malaysia (FF-2017-020, FF-2017-363 and FF-2017-273).

\section{Availability of data and materials}

The datasets generated and/or analysed during the current study are not publicly available due to patient anonymity and university confidentiality but are available from the corresponding author on reasonable request.

\section{Authors' contributions}

RAR, NAHNAE, TJ, MAAH, NQA and NFI carries out experiment, analysed data and wrote the manuscript together. NQAVS, MDY, YL supervised the experiments and data analysis, as well as critically commented on the manuscript. ABS is the surgeon who helped to procure the nasal turbinate sample, as well as critically commented on the manuscript. RBHI is the corresponding author for this manuscript, principal investigator of the project, supervised the experiment and data analysis, as well as critically commented on the manuscript and given final approval of this version to be published. All authors read and approved the final version of the manuscript.

\section{Ethics approval and consent to participate}

Written consents from the patient undergone turbinectomy were obtained prior to the collection of sample. This study was approved by Universiti Kebangsaan Malaysia Research Ethics Committee (FF-2017-363).

\section{Consent for publication}

Not applicable

\section{Competing interests}

The authors declare that they have no competing interests.

\section{Publisher's Note}

Springer Nature remains neutral with regard to jurisdictional claims in published maps and institutional affiliations.

\section{Author details}

${ }^{1}$ Department of Physiology, Faculty of Medicine, Universiti Kebangsaan Malaysia Medical Centre, Universiti Kebangsaan Malaysia, Cheras, 56000 Kuala Lumpur, Malaysia. ${ }^{2}$ Tissue Engineering Centre, Faculty of Medicine, Universiti Kebangsaan Malaysia Medical Centre, Universiti Kebangsaan Malaysia, Cheras, 56000 Kuala Lumpur, Malaysia. ${ }^{3}$ Ear, Nose \& Throat Consultant Clinic, Ampang Puteri Specialist Hospital, 68000 Ampang, Selangor, Malaysia.

Received: 2 April 2018 Accepted: 6 June 2018

Published online: 26 June 2018

References

1. Osguthorpe JD. Adult rhinosinusitis: diagnosis and management. Am Fam Physician. 2001;63(1):69-76.

2. Toppila-Salmi S, van Drunen CM, Fokkens WJ, Golebski K, Mattila P, Joenvaara $\mathrm{S}$, et al. Molecular mechanisms of nasal epithelium in rhinitis and rhinosinusitis. Curr Allergy Asthma Rep. 2015;15(2):495.

3. Bachert C, Pawankar R, Zhang L, Bunnag C, Fokkens WJ, Hamilos DL, et al. ICON: chronic rhinosinusitis. World Allergy Organ J. 2014;7(25):1-28.

4. Mascarenhas JG, Maria V, Chen VG, Itamoto CH, Atallah C, Gregório LC, et al. Long-term outcomes of endoscopic sinus surgery for chronic rhinosinusitis with and without nasal polyps. Braz J Otorhinolaryngol. 2013;79(3):306-11.

5. Park II, Kang JJ, Shin JJ, Lee HH, Trichostatin A. Inhibits epithelial mesenchymal transition induced by TGF- $\beta 1$ in airway epithelium. PLoS One. 2016;11(8):1-14.

6. Hupin C, Gohy S, Bouzin C, Lecocq M, Polette M, Pilette C. Features of mesenchymal transition in the airway epithelium from chronic rhinosinusitis. Allergy Eur J Allergy Clin Immunol. 2014;69(11):1540-9.

7. Meng J, Zhou P, Liu Y, Liu F, Yi X, Liu S, et al. The development of nasal polyp disease involves early nasal mucosal inflammation and Remodelling. PLoS One. 2013;8(12):1-13.

8. Kalluri R, Weinberg RA. The basics of epithelial-mesenchymal transition. J Clin Invest. 2009;119(6)

9. Gonzalez DM, Medici D. Signaling mechanisms of the epithelialmesenchymal transition. Sci Signal. 2014;7(344):re8. 
10. Sataloff RT. Professional Voice, Fourth Edition: The Science and Art of Clinical Care, 3-Volume Set [Internet]. Plural Publishing, Incorporated; 2017. Available from: https://books.google.com.my/books?id=ImVGDWAAQBAJ

11. Stone RC, Pastar I, Ojeh N, Chen V, Liu S, Garzon Kl, et al. Epithelialmesenchymal transition in tissue repair and fibrosis. Cell T issue Res. 2017; 365(3):495-506.

12. Kumar R. Nuclear signaling pathways and targeting transcription in Cancer. New York: Humana Press; 2014

13. Kasai H, Allen JT, Mason RM, Kamimura T, Zhang Z. TGF- $\beta 1$ induces human alveolar epithelial to mesenchymal cell transition. Respir Res. 2005;15:1-16.

14. Xu J, Lamouille S, Derynck R. TGF- $\beta$-induced epithelial to mesenchymal transition. Cell Res. 2016;19(2):156-72.

15. Jang Y, Shin H, Choi HS, Ryu E-S, Kim MJ, Min SK, et al. Effects of dexamethasone on the TGF- $\beta 1$-induced epithelial-to-mesenchymal transition in human peritoneal mesothelial cells. Lab Investig [Internet]. 2013;93(2):194-206. Available from: https://doi.org/10.1038/labinvest.2012.166

16. Pawankar R, Nonaka M. Inflammatory mechanisms and remodeling in chronic rhinosinusitis and nasal polyps. Dermatol Sin. 2007;7(3):202-8.

17. Shin J, Kang J, Lee S, Park I, Lee H. Effect of doxycycline on epithelialmesenchymal transition via the p38/Smad pathway in respiratory epithelial cells. Am J Rhinol Allergy. 2017:71-8.

18. Zhao H, Wu Q-Q, Cao L-F, Qing H-Y, Zhang C, Chen Y-H, et al. Melatonin inhibits endoplasmic reticulum stress and epithelial-mesenchymal transition during bleomycin-induced pulmonary fibrosis in mice. PLoS One [Internet]. 2014:9(5):e97266. Available from: http://www.pubmedcentral.nih.gov/ articlerender.fcgi?artid=4018327\&tool=pmcentrez\&rendertype=abstract.

19. Park SH, Gong JH, Choi YJ, Kang MK, Kim YH, Kang YH. Kaempferol inhibits endoplasmic reticulum stress-associated mucus hypersecretion in airway epithelial cells and ovalbumin-sensitized mice. PLoS One. 2015;10(11):1-17.

20. et al Tripoli E, Giammanco M, Tabacchi G, Di Majo D, Giammanco S, La Guardia M, et al. The phenolic compounds of olive oil: structure, biological activity and beneficial effects on human health. Nutr Res Rev [Internet]. 2005;18(1):98-112. Available from: https://doi.org/10.1079/ NRR200495\%5Cnhttp://www.ncbi.n/m.nih.gov/pubmed/19079898

21. Khaliq A, Sabir SM, Ahmad SD, Boligon AA, Athayde ML, Jabbar A, et al. Antioxidant activities and phenolic composition of olive ( Olea europaea) leaves. Appl Bot Food Qual. 2015;88(1):16-21.

22. Owen RW, Giacosa A, Hull WE, Haubner R, Würtele G, Spiegelhalder B. Oliveoil consumption and health : the possible role of antioxidants. Lancet 2000;107-12.

23. Pitt J, Roth W, Lacor P, Blankenship M, Velasco P, De FF, et al. Alzheimer'sassociated $A \beta$ oligomers show altered structure, immunoreactivity and synaptotoxicity with low doses of oleocanthal. Toxicol Appl Pharmacol. 2009;

24. Elnagar AY, Sylvester PW, El SKA. (-)-Oleocanthal as a c-met inhibitor for the control of metastatic breast and prostate cancers. pdf Planta Med. 2011; 77(10):1013-9.

25. Vazquez-Martin A, Fernández-Arroyo S, Cufí S, Oliveras-Ferraros C, LozanoSánchez J, Vellón L, et al. Phenolic Secoiridoids in extra virgin olive oil impede Fibrogenic and oncogenic epithelial-to-mesenchymal transition: extra virgin olive oil as a source of novel antiaging phytochemicals. Rejuvenation Res. 2012;15(1):3-21

26. Akl MR, Ayoub NM, Mohyeldin MM, Busnena BA, Foudah Al, Liu YY, et al. Olive phenolics as c-met inhibitors: (-)-Oleocanthal attenuates cell proliferation, invasiveness, and tumor growth in breast cancer models. PLoS One. 2014;9(5):e97622.

27. Hashmi MA, Khan A, Hanif M, Farooq U, Perveen S, Hashmi MA, et al. Traditional Uses, Phytochemistry, and Pharmacology of Olea europaea (Olive). Evidence-Based Complement Altern Med [Internet]. 2015;2015:1-29. Available from: http://www.hindawi.com/journals/ecam/2015/541591/

28. Razali RA, Lokanathan Y, Man RC, Chowdhury SR, Bin SA, RBH I. Surface modification of electrospun poly ( methyl methacrylate ) ( PMMA ) nanofibers for the development of in vitro respiratory epithelium model. $J$ Biomater Sci Polym Ed. 2015:26(October):0-32.

29. Menendez JA, Vazquez-martin A, Oliveras-ferraros C, Garcia-villalba R, Carrasco-pancorbo A. Extra-virgin olive oil polyphenols inhibit HER2 ( erb B-2) -induced malignant transformation in human breast epithelial cells : relationship between the chemical structures of extra-virgin olive oil secoiridoids and lignans and their inhibitory activitie. Int J Oncol. 2009; $2 \cdot 43-51$
30. Lo UG, Lee CF, Lee MS, Hsieh JT. The role and mechanism of epithelial-tomesenchymal transition in prostate cancer progression. Int J Mol Sci. 2017;18(10): 1-18.

31. Fogli S, Arena C, Carpi S, Polini B, Bertini S, Digiacomo M, et al. Cytotoxic activity of Oleocanthal isolated from virgin olive oil on human melanoma cells. Nutr Cancer. 2016;68(5):873-7.

32. García-Martínez O, De Luna-Bertos E, Ramos-Torrecillas J, Ruiz C, Milia E, Lorenzo $\mathrm{ML}$, et al. phenolic compounds in extra virgin olive oil stimulate human osteoblastic cell proliferation. PLoS One [Internet]. 2016;11(3): e0150045. Available from: https://doi.org/10.1371/journal.pone.0150045

33. Konnecke $M$, Burmeister M, Pries $R$, Boscke $R$, Bruchhage $K L$, Ungefroren $H$, et al. Epithelial-mesenchymal transition in chronic rhinosinusitis: differences revealed between epithelial cells from nasal polyps and inferior Turbinates. Arch Immunol Ther Exp. 2016;65:1-17.

34. Willis BC, Borok Z. TGF-B-induced EMT mechanisms and implications for fibrotic lung diseas. pdf Am J Physiol Lung Cell Mol Physiol. 2007;293(3): L525-34.

35. Zaravinos A, Emt T. The regulatory role of MicroRNAs in EMT and Cancer. J Oncol. 2015;2015:865816.

36. Lamouille $\mathrm{S}, \mathrm{Xu}$ J, Derynck R. Molecular mechanisms of epithelialmesenchymal transition. Nat Rev Mol cell Biol. 2014;15(3):178-96.

\section{Ready to submit your research? Choose BMC and benefit from:}

- fast, convenient online submission

- thorough peer review by experienced researchers in your field

- rapid publication on acceptance

- support for research data, including large and complex data types

- gold Open Access which fosters wider collaboration and increased citations

- maximum visibility for your research: over $100 \mathrm{M}$ website views per year

At BMC, research is always in progress.

Learn more biomedcentral.com/submissions 